\title{
Aspirin desensitization in patients with aspirin-induced and aspirin-tolerant asthma: A double-blind study
}

\author{
Monika Świerczyńska-Krępa, MD, PhD, ${ }^{a}$ Marek Sanak, MD, PhD, ${ }^{b}$ Grażyna Bochenek, MD, PhD, ${ }^{b}$ Paweł Stręk, MD, PhD, ${ }^{c}$ \\ Adam Ćmiel, PhD, ${ }^{d}$ Anna Gielicz, PhD, ${ }^{b}$ Hanna Plutecka, PhD, ${ }^{b}$ Andrzej Szczeklik, MD, PhD, ${ }^{b_{\dagger}}$ and \\ Ewa Niżankowska-Mogilnicka, MD, PhD $\quad$ Bielsko-Biała and Krakow, Poland
}

Background: Numerous open trials have demonstrated the beneficial clinical effects of aspirin desensitization (AD) in patients with aspirin-induced asthma (AIA). These beneficial effects might be attributable to aspirin's potent anti-

inflammatory properties, but that supposition requires further corroboration.

Objective: We sought to compare the clinical and biochemical responses to chronic oral $A D$ in 20 patients with AIA and 14 patients with aspirin-tolerant asthma (ATA). All of the patients had chronic rhinosinusitis and nasal polyposis, and these responses were investigated in a pilot, double-blind, placebocontrolled study.

Methods: Twelve patients with AIA and 6 patients with ATA were randomly assigned to receive $624 \mathrm{mg}$ of aspirin, and 8 patients with AIA and 8 patients with ATA received placebo. Both aspirin and placebo were administered once daily for 6 months. Nasal symptoms, Sino-Nasal Outcome Test (SNOT20) scores, peak nasal inspiratory flows, Asthma Control Questionnaire scores, spirometric parameters, peak expiratory flows, blood eosinophilia, and corticosteroid doses were assessed on a monthly basis. Levels of urinary leukotriene $E_{4}$ and the stable plasma prostaglandin (PG) $\mathrm{D}_{2}$ metabolite $9 \alpha, 11 \beta-P G F 2$ were evaluated at baseline and after $1,3,5$, and 6 months. Results: Only the patients with AIA subjected to AD reported improvements in smell and reductions in sneezing and nasal blockade. The SNOT20 and Asthma Control Questionnaire scores of these patients decreased, and their peak nasal inspiratory flows increased. The dosages of inhaled corticosteroids were reduced. There were no changes in leukotriene $\mathrm{E}_{4}$ or $9 \alpha, 11 \beta-\mathrm{PGF}_{2}$ levels after $\mathrm{AD}$.

\footnotetext{
$\overline{\text { From }}{ }^{\mathrm{a} M e d e x}$, Bielsko-Biała; ${ }^{\mathrm{b}}$ the Division of Pulmonology, Department of Medicine, and ${ }^{c}$ the Department of Otolaryngology, Jagiellonian University School of Medicine, Krakow; and ${ }^{\mathrm{d}}$ the Department of Applied Mathematics, AGH University of Science and Technology, Krakow.

$\dagger$ Deceased.

Supported by university grant no. K/ZDS/000362 (Ministry of Science and Higher Education of Poland in association with Jagiellonian University).

Disclosure of potential conflict of interest: M. Świerczyńska-Krępa, G. Bochenek, P. Stręk, A. Ćmiel, A. Gielicz, H. Plutecka, and E. Niżankowska-Mogilnicka have received research support from the Ministry of Science and Higher Education of Poland in association with Collegium Medicum Jagiellonian University (grant no. K/ZDS/000362). M. Sanak has received a grant from Switzerland through the Swiss Contribution to the enlarged European Union (PSPB-072/2010) and a grant from Iceland, Liechtenstein, and Norway through the European Economic Area (EEA) U-BIOPPRED, EU, and EFPIA within the Innovative Medicines Initiative (IMI).

Received for publication August 2, 2013; revised February 23, 2014; accepted for publication February 28, 2014

Available online April 24, 2014.

Corresponding author: Ewa Niżankowska-Mogilnicka, $\mathrm{MD}, \mathrm{PhD}$, Division of Pulmonology, Department of Medicine, Jagiellonian University School of Medicine, ul. Skawińska 8, 31-066 Krakow, Poland. E-mail: ewa.nizankowska@ghml.pl. $0091-6749 / \$ 36.00$

(C) 2014 American Academy of Allergy, Asthma \& Immunology

http://dx.doi.org/10.1016/j.jaci.2014.02.041
}

Conclusion: The clinically beneficial effects of $A D$ on nasal and bronchial symptoms occurred only in the patients with AIA. (J Allergy Clin Immunol 2014;134:883-90.)

Key words: Aspirin-induced asthma, aspirin-tolerant asthma, oral aspirin desensitization

Aspirin-induced asthma (AIA) (also called aspirin-exacerbated respiratory disease) is a clinical syndrome consisting of asthma, rhinosinusitis with nasal polyps, and hypersensitivity to aspirin (acetylsalicylic acid [ASA]) and/or other nonsteroidal anti-inflammatory drugs (NSAIDs) that block COX-1. ${ }^{1-6}$ Complex alterations in the eicosanoid pathway that involve the overproduction of proinflammatory cysteinyl leukotrienes (cysLTs) and prostaglandin (PG) $\mathrm{D}_{2}$ and decreased synthesis of anti-inflammatory $\mathrm{PGE}_{2}$ and lipoxins have been reported in patients with AIA. ${ }^{1-7}$

Aspirin desensitization (AD) can improve rhinosinusitis and the course of uncontrolled asthma in patients with AIA. ${ }^{1-3,5,6}$ Many authors have investigated AD with different protocols and routes of administration..$^{1-3,5,6,8-35}$ However, the most notable work in this field is credited to the group from the Scripps Clinic in La Jolla, California. ${ }^{3,5,6,8,9,25-35}$ In 1984, Stevenson et $\mathrm{al}^{26}$ reported clinical improvements in 25 patients with AIA after 3 months of $\mathrm{AD}$ in a double-blind crossover study. However, this study did not include any patients with aspirin-tolerant asthma (ATA) to facilitate the analysis of the specificity of AD. Subsequently, larger retrospective and open studies were published. ${ }^{5-8,27-35}$ Most of these studies assessed the influence of $\mathrm{AD}$ on the alterations of eicosanoid metabolism that have been implicated in the pathogenesis of AIA..$^{16,22,28-30}$ The effects of $\mathrm{AD}$ might be attributable to the potent anti-inflammatory action of aspirin. $^{36}$ A prospective, double-blind, parallel-group, placebo-controlled study assessing the clinical effects and alterations of the eicosanoid pathway caused by oral $\mathrm{AD}$ in both the AIA and ATA groups is still pending. If proved effective, AD might also be of great value in patients with ATA accompanied by rhinosinusitis and nasal polyps.

Therefore we studied the clinical and biochemical responses to a 6-month oral AD regimen in 20 patients with AIA and 14 patients with ATA in a pilot double-blind, placebo-controlled study.

\section{METHODS \\ Patients}

The inclusion criteria were as follows: (1) age of 18 to 65 years; (2) asthma diagnosed in compliance with applicable guidelines ${ }^{37}$; (3) rhinosinusitis with nasal polyps as evidenced by medical records and endoscopic findings, computed tomographic (CT) findings, or both ${ }^{38}$; (4) a positive history of a prior reaction to aspirin, other NSAIDs, or both confirmed by a positive 
Abbreviations used

ACQ: Asthma Control Questionnaire

AD: Aspirin desensitization

AIA: Aspirin-induced asthma

ASA: Acetylsalicylic acid

ATA: Aspirin-tolerant asthma

CT: Computed tomography

cysLT: Cysteinyl leukotriene

ICS: Inhaled corticosteroid

L-ASA: Lysine-aspirin

LTE$_{4}$ : Leukotriene $\mathrm{E}_{4}$

NSAID: Nonsteroidal anti-inflammatory drug

PEF: Peak expiratory flow

PG: Prostaglandin

$9 \alpha, 11 \beta-\mathrm{PGF}_{2}: 9 \alpha, 11 \beta$-Prostaglandin $\mathrm{F}_{2}$

PNIF: Peak nasal inspiratory flow

SNOT20: Sino-Nasal Outcome Test

uLTE$_{4}$ : Urinary $\mathrm{LTE}_{4}$

response to oral aspirin challenge for the patients with AIA; and (5) a negative history of aspirin hypersensitivity and a negative response to aspirin challenge for the patients with ATA. The exclusion criteria were as follows: (1) a history of life-threatening anaphylactic reactions precipitated by NSAIDs; (2) uncontrolled asthma, $\mathrm{FEV}_{1}$ of less than $70 \%$ of predicted value, or both; (4) autoimmune diseases; (5) severe diseases of the heart or digestive, urinary, or neurologic systems or any other clinical condition that could potentially influence the study outcome; (6) neoplasm; and (7) pregnancy. Leukotriene modifiers, omalizumab, and immunotherapy or other immunomodulator drugs were prohibited throughout the study.

\section{Trial design}

All patients provided written informed consent in which they indicated that they had been informed that they might or might not benefit from the AD and that it is not known whether the effects of the potent anti-inflammatory drug aspirin are beneficial to patients with ATA. The study was approved by the local bioethics review committee. The study was a randomized, double-blind, placebo-controlled, parallel-group study. A total of 109 patients were screened, 44 of whom were ultimately considered eligible for the study (Fig 1). Ten of the 44 eligible patients did not enter the study ( 4 had preplanned sinus surgeries, 5 withheld their consent for the study, and 1 had a positive response to placebo challenge). In total, 34 patients underwent a single-blind, 2-day, placebo-controlled oral aspirin challenge that sought to establish the minimum dose of aspirin that provoked typical symptoms of aspirin hypersensitivity or to conclusively rule out any aspirin hypersensitivity (Fig 1). Subsequently, 20 patients with AIA and 14 patients with ATA were randomized (by using random number tables) to a 6-month oral $\mathrm{AD}$ (624 mg once daily) group or a 6-month placebo intake (once daily) group. Aspirin and placebo (lactose) were prepared by a hospital pharmacy in the form of identical, powder-packed gelatin capsules.

\section{Aspirin challenge and desensitization}

Oral aspirin challenges were conducted. ${ }^{20}$ On the first day, placebo was administered 4 times every 1.5 hours. On the second day, the patients received 4 increasing doses of aspirin every 1.5 hours (27, 44, 117 and $312 \mathrm{mg}$; cumulative aspirin dose, $500 \mathrm{mg}$ ). Clinical symptoms, such as dyspnea, rhinorrhea, nasal blockade, sneezing, ocular secretion, and skin flushing, were assessed. Serial spirometry (abcPneumo 2000RS; abcMED, Krakow, Poland) and peak nasal inspiratory flow (PNIF; the Youlten PNIFmeter; Clement Clarke International, Harlow, United Kingdom) measurements were performed every 30 minutes. Positive reactions to aspirin were defined by the appearance of clinical symptoms accompanied by decreases of at least $20 \%$ in $\mathrm{FEV}_{1}$ relative to baseline values.

\section{Randomization to AD or placebo administration}

On the day after the aspirin challenge, the 12 patients with AIA randomized to the $\mathrm{AD}$ group (AIA-ASA) received the maximal dose of aspirin they had tolerated during the aspirin challenge. If the patient remained asymptomatic, this dose was followed by administrations of the incrementally higher dose of aspirin 1.5 hours apart until the daily cumulative dose of at least $624 \mathrm{mg}$ was reached. If a patient demonstrated a clinical reaction to this dose or a $20 \%$ decrease in $\mathrm{FEV}_{1}$ occurred before the cumulative dose of $624 \mathrm{mg}$ of aspirin was reached, AD was restarted the following day with the dose that had had provoked the reaction the day before. Consequently, the day of "acute desensitization" was defined as the day on which the patient was able to ingest a single daily dose of $624 \mathrm{mg}$ of aspirin in the morning without any reaction (this usually took 1-3 days). That day was also the first day of chronic AD, which was then pursued for up to 6 months.

The six patients with ATA randomized to AD (ATA-ASA) were given $624 \mathrm{mg}$ of aspirin once daily on the day after their negative response to the aspirin challenge and continued this daily dose for 6 months.

The other 8 patients with AIA (AIA-placebo) and 8 patients with ATA (ATA-placebo) were randomized to placebo administration for 6 months and received placebo on the day after the aspirin challenge.

\section{Assessments}

Clinical evaluations. At baseline and during the $\mathrm{AD}$ or placebo administration procedures (6 visits [V1-V6] every $30 \pm 7$ days), the patients were examined by a blinded physician. Asthma Control Questionnaire (ACQ) and Sino-Nasal Outcome Test (SNOT20) scores were analyzed, and $\mathrm{FEV}_{1}$, peak expiratory flow (PEF; Mini-Wright Peak Flow Meter, Clement Clarke International; best of 3 efforts), and PNIF values were measured. Doses of inhaled corticosteroids (ICSs) and nasal corticosteroids were kept stable throughout the aspirin challenge and acute desensitization; during the 6-month course of chronic $\mathrm{AD}$, these doses were altered according to the clinical status of the patients. The patients also completed diaries with scores for nasal (smell, nasal blockade, sneezing, rhinorrhea, postnasal drip, and nasal itching) and bronchial (cough and dyspnea) symptoms that were assessed on a visual analog scale ( 0 , none; 10 , the most severe). All adverse events were duly recorded. Before entering the trial, all but 1 patient underwent spiral CT scans of the sinuses (ElScint Flash, Haifa, Israel), and the results were evaluated by an experienced radiologist according to the Lund-Mackay score. ${ }^{39}$ In 21 patients sinus CT scans were repeated after 6 months (for details, see the Results section).

Laboratory evaluations. Urine samples were collected for the assessment of leukotriene $\mathrm{E}_{4}\left(\mathrm{LTE}_{4}\right)$ excretion at baseline and after 6 hours on the first day (placebo) and on the following day (aspirin challenge). Samples were also collected on the day of acute $\mathrm{AD}$ and during the actual visits in the first (V1), third (V3), fifth (V5), and sixth (V6) months of AD or placebo administration. Urinary $\mathrm{LTE}_{4}\left(\mathrm{uLTE}_{4}\right)$ levels were assessed with the enzyme immunoassay method (Cayman Chemicals, Ann Arbor, Mich). ${ }^{40}$

Blood plasma was taken to assess $9 \alpha, 11 \beta$-prostaglandin $\mathrm{F}_{2}\left(9 \alpha, 11 \beta-\mathrm{PGF}_{2}\right)$ levels at the same time points. Gas chromatography-negative ion chemical ionization mass spectrometry (model 5896 series II; Hewlett Packard, Palo Alto, Calif) was used to measure $9 \alpha, 11 \beta-\mathrm{PGF}_{2}$ levels. ${ }^{41}$

Additionally, on the first day of the aspirin challenge and during visits $\mathrm{V} 1$ to V6, blood absolute eosinophil counts were assessed. All measurements were compared against the baseline measurements taken on the placebo day of the challenge procedure.

\section{Statistical analyses}

The primary end points of the study were the following: the clinical efficacy of $\mathrm{AD}$ (ie, the changes in the scores for the clinical symptoms); PNIF, FEV ${ }_{1}$, and PEF values; and absolute reductions in corticosteroid doses. The secondary end points were changes in uLTE $4, \mathrm{p} 9 \alpha, 11 \beta-\mathrm{PGF}_{2}$, or both levels after AD.

Statistical evaluations were performed with STATISTICA 10 software (StatSoft, Tulsa, Okla) for Windows. Summary statistics are expressed as the median and interquartile range in the tables when not otherwise stated. Oneway and multi-way ANOVAs with the Tukey post hoc procedure for testing multiple comparisons were used to compare the groups during $\mathrm{AD}$ (only significant results, expressed as the mean and SD, are listed in the Results section). Logarithmic transformations were used to stabilize variance. Mann-Whitney 


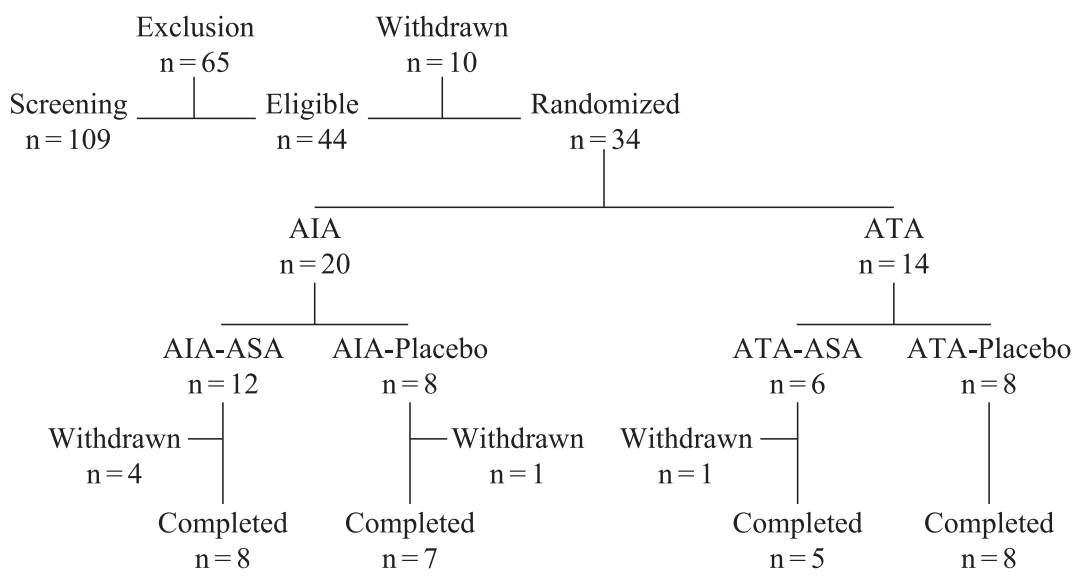

FIG 1. Study flowchart.

$U$ tests were used to compare clinical/treatment data across groups. Fisher exact tests were used to assess the significance of differences in the $2 \times 2$ tables. $P$ values of .05 or less were considered statistically significant.

\section{RESULTS \\ Patients}

Twenty-eight of the 34 patients completed the 6-month AD or placebo administration regimen (AIA-ASA: $\mathrm{n}=8$, AIA-placebo: $\mathrm{n}=7$, ATA-ASA: $\mathrm{n}=5$, ATA-placebo: $\mathrm{n}=8$; Fig 1 ; for the reasons for discontinuation, see the section on the adverse events related to $\mathrm{AD})$. The patient groups were comparable in the majority of baseline characteristics (Tables I and II). Selected specific outcomes of the subjects are presented in Table E1 in this article's Online Repository at www.jacionline.org.

\section{Clinical evaluations}

Chronic AD resulted in significant improvements in asthma control and less intensive therapy only for the patients with AIA (AIA-ASA). By the sixth month of chronic AD (ie, at visit 6), ACQ scores decreased in the AIA-ASA group compared with those in the AIA-placebo group $(P=.037$, Fig 2). The ICS doses of the AIA-ASA group were also lower than those of the AIA-placebo group ( $P=.03$, Fig 2). Asthma symptoms, $\mathrm{FEV}_{1}$ and PEF values, and use of rescue medications did not change in any studied group throughout the 6-month chronic AD course. There were no hospitalizations caused by asthma exacerbation.

AD diminished the severity of rhinosinusitis only in the patients with AIA. Compared with baseline, SNOT20 scores decreased at visits V1 $(P=.001), \mathrm{V} 2(P=.002), \mathrm{V} 3(P=.08), \mathrm{V} 4$ $(P=.04)$, and V5 $(P=.04)$ only in the AIA-ASA group, and these values remained unaltered in the other 3 groups (Fig 3). At V6, PNIF values increased compared with baseline values only in the AIA-ASA group $(P=.001$, Fig 3$)$. Improvements in smell were observed in 5 of the 8 patients with AIA after 6 months of $\mathrm{AD}$ ( 2 of the 7 taking placebo exhibited improvements in smell). Smell scores on V1 and V6 were lower than those at baseline only in the AIA-ASA group $(P=.01$ and .046 , respectively; see Fig E1 in this article's Online Repository at Www.jacionline.org). Sneezing scores decreased significantly compared with those at baseline at V1 $(P=.02), \mathrm{V} 3(P=.005), \mathrm{V} 4(P=.02)$, and V5 $(P=.02)$, and nasal blockade decreased significantly compared with that seen at baseline at V2 $(P=.049)$ in only the
TABLE I. Clinical characteristics of the patients with AIA and those with ATA

\begin{tabular}{|c|c|c|c|}
\hline & $\begin{array}{l}\text { Patients } \\
\text { with AIA } \\
(\mathrm{n}=20)\end{array}$ & $\begin{array}{c}\text { Patients } \\
\text { with ATA } \\
\text { (n= 14) }\end{array}$ & $\begin{array}{c}P \\
\text { value }\end{array}$ \\
\hline Age (y) & $46.0 \pm 19.0$ & $49.5 \pm 15.0$ & .38 \\
\hline Sex (female/male ratio) & $15 / 5$ & $9 / 5$ & .70 \\
\hline Aspirin hypersensitivity duration (y) & $8.0 \pm 8.5$ & NA & \\
\hline Asthma duration $(\mathrm{y})$ & $7.0 \pm 7.0$ & $8.4 \pm 9.0$ & .16 \\
\hline Rhinitis duration (y) & $13.5 \pm 12.0$ & $13.5 \pm 15.0$ & .88 \\
\hline Nasal polyposis duration $(\mathrm{y})$ & $8.0 \pm 9.0$ & $4.0 \pm 13.0$ & .55 \\
\hline No. of polypectomies per patient & $2 \pm 4$ & $1.5 \pm 2$ & .52 \\
\hline Polypectomy/no polypectomy & $17 / 3$ & $11 / 3$ & .67 \\
\hline ICSs $(\mu \mathrm{g})^{*}$ & $800 \pm 600$ & $800 \pm 400$ & .04 \\
\hline Nasal corticosteroids $(\mu \mathrm{g})^{*}$ & $100 \pm 100$ & $100 \pm 28$ & .99 \\
\hline Baseline $\mathrm{FEV}_{1}$ (\% predicted) & $88.7 \pm 17.8$ & $92.5 \pm 30.9$ & .50 \\
\hline Baseline PEF (L/min) & $420 \pm 148$ & $400 \pm 195$ & .82 \\
\hline Baseline PNIF (L/min) & $125 \pm 100$ & $195 \pm 100$ & .03 \\
\hline $\begin{array}{l}\text { Absolute eosinophil blood } \\
\text { count }\left(/ \mathrm{mm}^{3}\right)\end{array}$ & $509.5 \pm 465$ & $340 \pm 195$ & .08 \\
\hline SNOT20 & $1.9 \pm 1.0$ & $1.3 \pm 0.7$ & .08 \\
\hline ACQ score & $1.3 \pm 1.4$ & $0.9 \pm 1.0$ & .10 \\
\hline Serum $\operatorname{IgE}(\mathrm{IU} / \mathrm{mL})$ & $66.7 \pm 111.9$ & $107.5 \pm 90.2$ & .19 \\
\hline
\end{tabular}

Values are expressed as medians \pm interquartile ranges.

$N A$, Not applicable.

*Daily dose presented as budesonide equivalent.

AIA-ASA group (see Fig E1). Baseline sinus CT scores were higher in the patients with AIA $(n=20)$ than in the patients with ATA $(\mathrm{n}=13 ; 18.0 \pm 5.0$ vs $12.9 \pm 5.3$, respectively; $P=.01)$. Twenty-one of the 28 patients who completed the study agreed to undergo an additional sinus CT scan. The CT scores were similar to those at baseline in 7 patients in the AIA-ASA group (20.3 \pm 3.1 and $19.7 \pm 3.7$, respectively; $P=.76)$; 5 patients in the ATA-ASA group $(17.8 \pm 5.7$ and $17.4 \pm 5.2$, respectively; $P=.84), 3$ patients in the AIA-placebo group $(15.0 \pm 1.0$ and $15.7 \pm 1.5$, respectively; $P=.45)$, and 6 patients in the ATA-placebo group $(10.2 \pm 4.7$ and $11.2 \pm 6$, respectively; $P=.65)$.

\section{Laboratory evaluations}

Aspirin challenge. The responses to aspirin challenge were positive in all 20 patients with AIA and negative in all 14 patients 
TABLE II. Clinical characteristics of the 4 groups of patients: patients with AIA receiving AD (AIA-ASA), patients with AIA receiving placebo (AIA-placebo), patients with ATA receiving aspirin therapy (ATA-ASA), and patients with ATA receiving placebo (ATAplacebo)

\begin{tabular}{|c|c|c|c|c|c|c|}
\hline & AIA-ASA (n = 12) & AIA-placebo $(n=8)$ & $P$ value & ATA-ASA $(n=6)$ & ATA-placebo $(n=8)$ & $P$ value \\
\hline Age $(y)$ & $48.5 \pm 18.0$ & $39.5 \pm 27.0$ & .79 & $50.0 \pm 23.0$ & $49.0 \pm 15.0$ & .75 \\
\hline Sex (female/male ratio) & $9 / 3$ & $6 / 2$ & 1.0 & $1 / 5$ & $2 / 6$ & 1.0 \\
\hline Aspirin hypersensitivity duration (y) & $11.0 \pm 6.5$ & $6.0 \pm 4.5$ & .07 & NA & NA & NA \\
\hline Rhinitis duration (y) & $16.0 \pm 8.0$ & $7.5 \pm 7.5$ & .13 & $17.5 \pm 9.0$ & $8.5 \pm 10.0$ & .14 \\
\hline Nasal polyposis duration (y) & $10.1 \pm 8.5$ & $6.0 \pm 9.0$ & .47 & $14.0 \pm 19.0$ & $1.5 \pm 7.0$ & .18 \\
\hline No. of polypectomies per patient & $3.5 \pm 8$ & $1.5 \pm 2.0$ & .27 & $2.5 \pm 3.0$ & $1.0 \pm 1.5$ & .28 \\
\hline Nasal corticosteroids $(\mu \mathrm{g})^{*}$ & $114 \pm 100$ & $100 \pm 64$ & .24 & $100 \pm 100$ & $100 \pm 14$ & .57 \\
\hline Baseline $\mathrm{FEV}_{1}$ (\% predicted) & $84.6 \pm 23.0$ & $93.9 \pm 14.2$ & .52 & $92.5 \pm 23.7$ & $95.7 \pm 29.9$ & .66 \\
\hline Baseline PEF (L/min) & $445 \pm 148$ & $405 \pm 110$ & .79 & $357.5 \pm 10$ & $540 \pm 170$ & .03 \\
\hline Baseline PNIF (L/min) & $135 \pm 110$ & $125 \pm 100$ & .79 & $190 \pm 70$ & $195 \pm 165$ & .95 \\
\hline Eosinophil blood count $\left(/ \mathrm{mm}^{3}\right)$ & $429 \pm 642$ & $639 \pm 299$ & .38 & $352.5 \pm 288$ & $218 \pm 359$ & .37 \\
\hline SNOT 20 & $1.9 \pm 0.8$ & $1.8 \pm 1.2$ & .73 & $1.8 \pm 1.5$ & $1.1 \pm 06$ & .04 \\
\hline
\end{tabular}

Values are expressed as medians \pm interquartile ranges.

$N A$, Not applicable.

*Daily dose presented as budesonide equivalent.
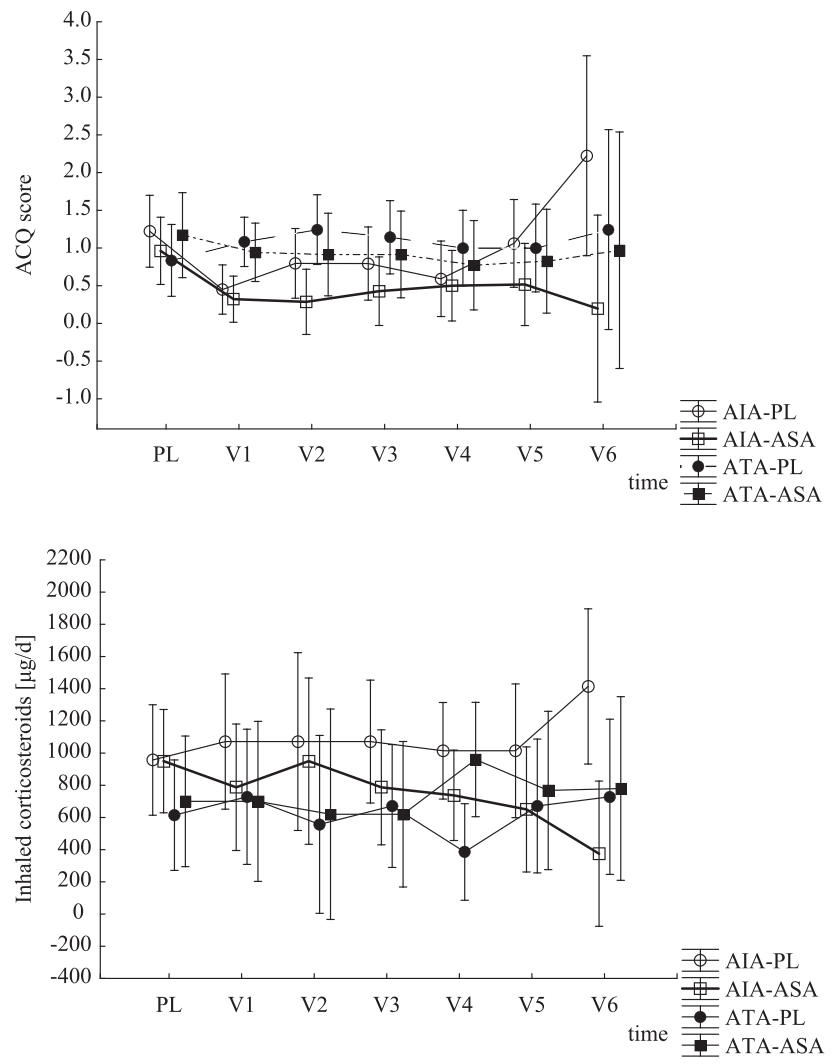

FIG 2. ACQ scores (7-point scale) and ICS doses at baseline and after 6 months of $A D$ or placebo intake. AIA-ASA versus AIA-placebo ACQ scores at $\mathrm{V} 6, P=.037$; AIA-ASA versus AIA-placebo ICS doses at $\mathrm{V} 6, P=.03$. Baseline, placebo day of aspirin challenge.

with ATA. The mean aspirin provocative dose of the AIA group was $287 \pm 161 \mathrm{mg}$. The mean baseline $\mathrm{uLTE}_{4}$ level of the AIA group was significantly higher than that of the ATA group
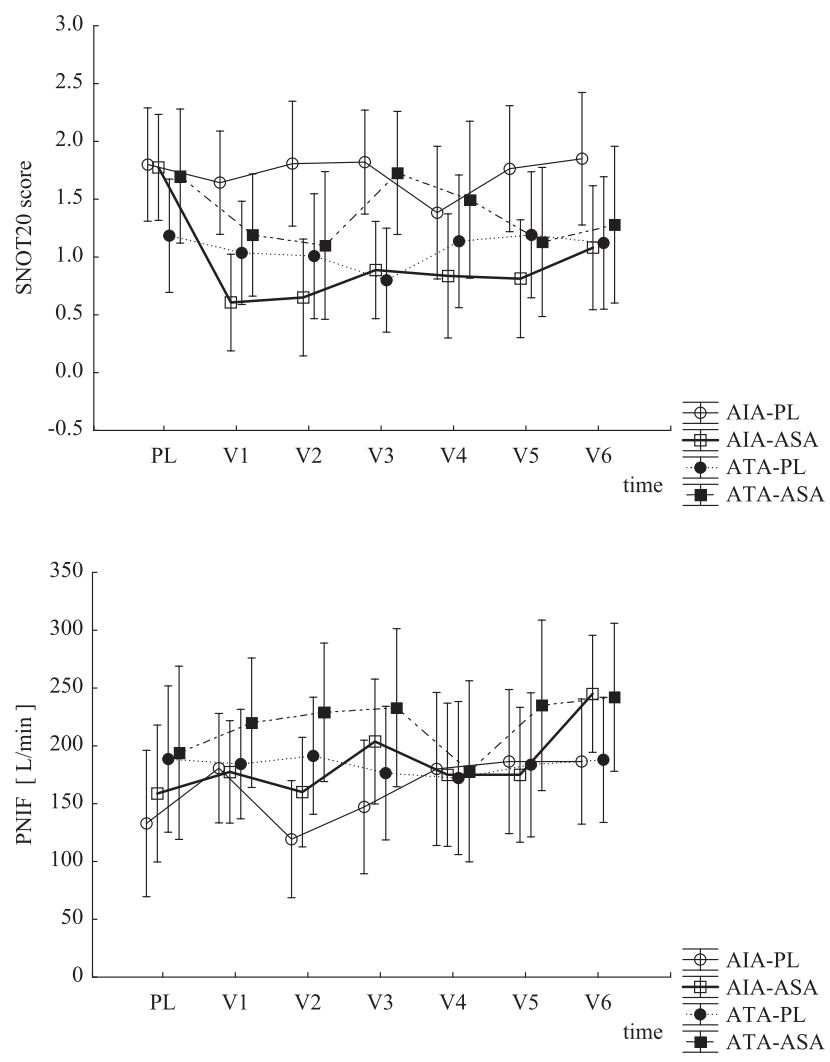

FIG 3. SNOT20 scores and PNIF values at baseline and after 6 months of $A D$ or placebo intake. SNOT20-AIA-ASA: placebo versus $\mathrm{V} 1, P=.001$; placebo versus $\mathrm{V} 2, P=.002$; placebo versus $\mathrm{V} 3, P=.08$; placebo versus $\mathrm{V} 4, P=.04$; placebo versus V5, $P=.04$. PNIF-AIA-ASA: placebo versus $\mathrm{V} 6, P=.001$. Baseline, placebo day of aspirin challenge.

$(3794.5 \pm 7355.4$ vs $1439.6 \pm 2722.0 \mathrm{pg} / \mathrm{mg}$ creatinine, respectively; $P=.01$; Fig 4$)$. Compared with baseline, excretion of $\mathrm{ULTE}_{4}$ exhibited further increases only in the AIA group after 

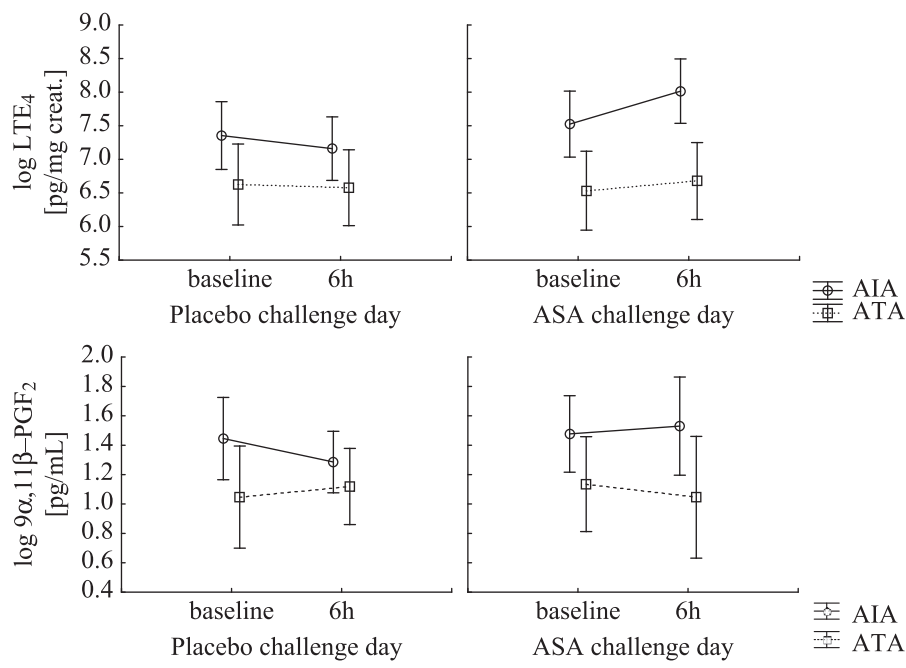

FIG 4. ULTE 4 and plasma $9 \alpha, 11 \beta-$ PGF $_{2}$ levels (both expressed as log changes over time) at baseline and after aspirin challenge. Baseline uLTE $\mathrm{LIIA}_{4}$ versus ATA, $P=.01$; uLTE 4 in patients with AlA before versus after aspirin challenge, $P<.001$. Baseline $p 9 \alpha, 11 \beta-\mathrm{PGF}_{2}$ : AIA versus ATA, $P=.03$. No further increases after aspirin challenge were observed.

aspirin challenge $(5445.1 \pm 8312.9$ vs $3794.5 \pm 7355.4 \mathrm{pg} / \mathrm{mg}$ creatinine, respectively; $P<.001$; Fig 4$)$.

The mean baseline $\mathrm{p} 9 \alpha, 11 \beta-\mathrm{PGF}_{2}$ level of the AIA group was significantly higher than that of the ATA group (5.77 vs $3.1 \pm 1.1$ $\mathrm{pg} / \mathrm{mL}$, respectively; $P=.03$ ), and no further increases after aspirin challenge were observed (Fig 4).

Six-month chronic AD or placebo intake. The baseline $\mathrm{uLTE}_{4}$ levels of both the AIA-placebo and AIA-ASA groups were higher than that of the ATA-placebo group (7439.8 \pm 10970.3 and $1364.3 \pm 869.3$ vs $724.7 \pm 565.8 \mathrm{pg} / \mathrm{mg}$ creatinine; $P=.002$ and $P=.007$, respectively) and similar to that of the ATA-ASA group $(2392.8 \pm 4112.2 \mathrm{pg} / \mathrm{mg}$ creatinine $)$. Neither chronic AD nor placebo intake altered $\mathrm{uLTE}_{4}$ levels in any of the 4 groups (Fig 5).

The $\mathrm{p} 9 \alpha, 11 \beta-\mathrm{PGF}_{2}$ levels and blood eosinophil counts, analyzed separately within the 4 groups, were comparable at baseline and across the 6-month $\mathrm{AD}$ or placebo intake period (Fig 5).

Adverse events related to AD. In total, 6 study subjects dropped out of the study (Fig 1). One patient with AIA in the placebo group dropped out because of the lack of improvement. Five patients ( 4 patients with AIA and 1 patient with ATA) dropped out because of dyspepsia during chronic AD. One patient with AIA also had a transient skin rash.

\section{DISCUSSION}

In recent decades, several observational studies and 1 doubleblind study (without an ATA control group) ${ }^{26}$ have demonstrated the clinical efficacy of oral AD in patients with AIA. ${ }^{2,3,8,9,26}$ Oral $\mathrm{AD}$ improves nasal and bronchial symptoms; patients require fewer corticosteroids and antibiotics for upper respiratory tract infections and fewer emergency department visits, hospitalizations, outpatient visits, and sinus surgeries. ${ }^{2,3,8,9,26}$ Moreover, open observations of nasal desensitization have revealed that lysine-aspirin (L-ASA) reduces the frequency of nasal polyp relapse and increased PNIF values in patients with AIA compared with values seen in untreated control subjects. ${ }^{14,19,24}$
Nevertheless, the first double-blind crossover trial of patients with AIA (22 patients) did not demonstrate any significant improvement in acoustic rhinometry parameters, PNIF values, PEF values, or symptom scores after 6 months of nasal L-ASA desensitization. ${ }^{18}$ Thus the positive effects of AD have typically been observed in uncontrolled trials. It was also previously unclear whether a beneficial effect of AD would be observed only in patients with AIA. Improvements in patients with AIA and those with ATA after open nasal L-ASA desensitization have been reported. ${ }^{15}$

Recent studies have demonstrated the newly discovered properties of aspirin in regulating the immune system that extend beyond those related to $\mathrm{COX}$ inhibition. ${ }^{42,43}$ Aspirin inhibits $\mathrm{T}$-cell proliferation, cytokine production, activation of NF- $\mathrm{B}$ during transcription of proinflammatory cytokines, and antibody production. $^{42,43}$

Our pilot, prospective, placebo-controlled parallel-group study is the first to prove that the positive effect of oral AD might only occur in patients with AIA.

We demonstrated that 6 months of chronic oral AD led to clinical improvements in asthma control in patients with AIA; these improvements were expressed as decreases in ACQ scores and reductions in ICS doses. Asthma improvement has also been observed in an open study during a 6-month AD course. ${ }^{32}$ In contrast to the aforementioned study, ${ }^{32}$ we were able to detect a favorable effect of $\mathrm{AD}$ only on maintenance doses of ICSs. This discrepancy might be attributable to the fact that the other investigators $^{32}$ used a dose of ASA $(1300 \mathrm{mg})$ that was twice that of the dose used here.

Similar to other reports, our patients with AIA receiving AD therapy reported long-lasting returns of their sense of smell relatively early. ${ }^{32,33}$ In our study sneezing and nasal blockade scores decreased significantly only in the AIA-ASA group, and the majority of relevant studies have reported similar results. ${ }^{5}$ Furthermore, we demonstrated that scores on the well-standardized SNOT20 decreased significantly only in the AIA-ASA group, which effectively corroborates the results of Katial et al. ${ }^{22}$ 

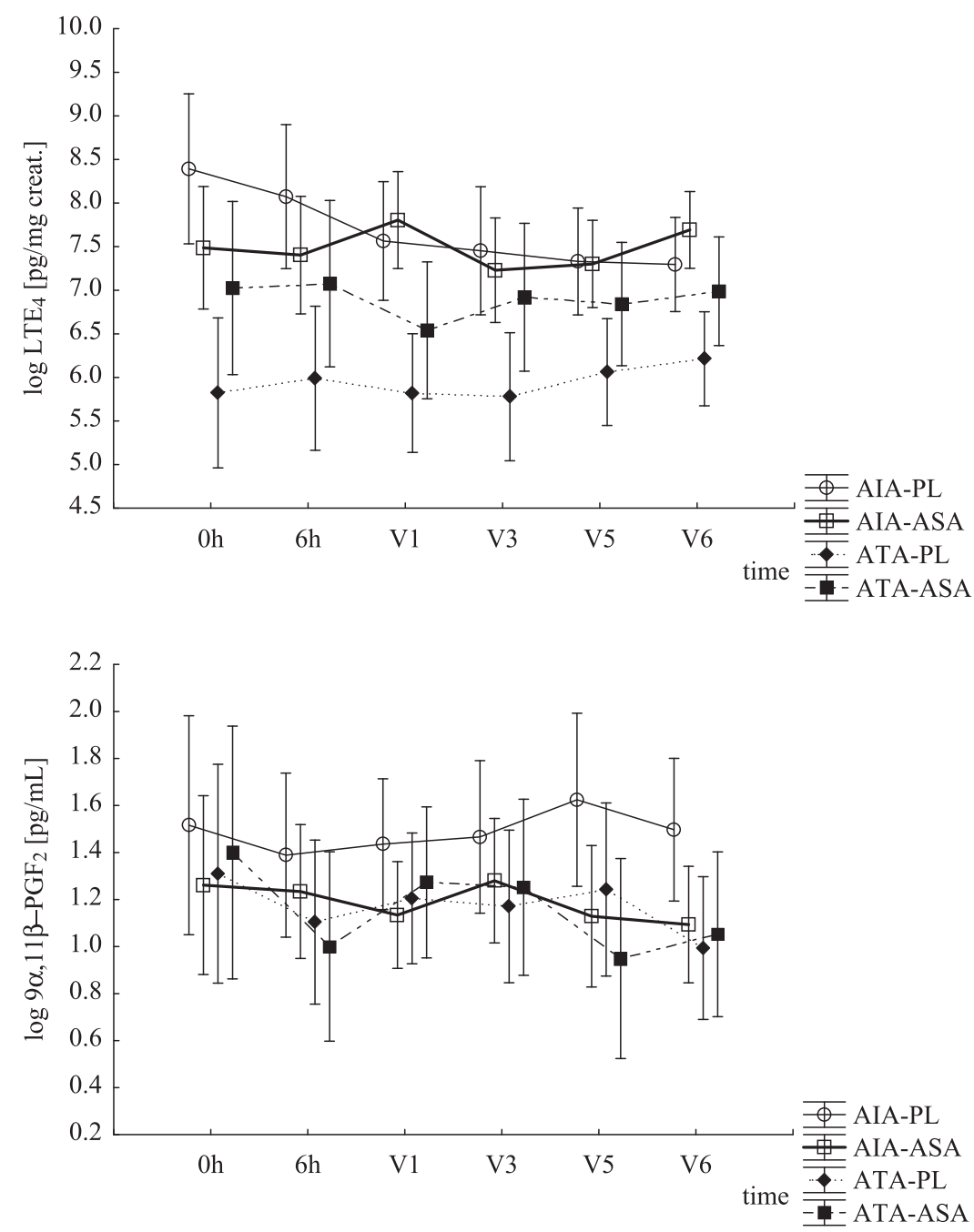

FIG 5. uLTE $_{4}$ and plasma $9 \alpha, 11 \beta-\mathrm{PGF}_{2}$ levels (both expressed as log changes over time) at baseline and throughout $\mathrm{AD}$ or placebo intake. Baseline $\mathrm{uLTE}_{4}$ : AIA-ASA versus ATA-placebo, $P=.007$; AIA-placebo versus $A T A$-placebo, $P=.002$. Neither $A D$ nor placebo intake altered $u L T E_{4}$ or $p 9 \alpha, 11 \beta-P G F_{2}$ levels.

Notably, we used objective outcome measurements (eg, nasal and pulmonary function tests and sinus CT scans) that have seldom been used to evaluate the effects of AD. Six months of AD resulted in significant improvements in PNIF values in our patients with AIA, but $\mathrm{FEV}_{1}$ and PEF values remained unaltered. To the best of our knowledge, the present study is the first to assess sinus CT scans in patients undergoing $\mathrm{AD}$. Unfortunately, no improvements were observed in Lund-Mackay scores. Similarly, another study that used radiographs of the paranasal sinuses observed no obvious effects on these images after $\mathrm{AD} .{ }^{14}$ The relatively short duration of $\mathrm{AD}$ and the small number of $\mathrm{CT}$ scans analyzed might account for this discrepancy. Six months of AD might be insufficient to detect differences in numbers of sinus surgeries because these differences tend to become evident within at least 1 year of the actual therapy. ${ }^{33}$ The effect of $\mathrm{AD}$ is more evident when the occurrences of nasal polyp relapses after surgery are evaluated..$^{24,31,33}$ Our patients were not directly subjected to sinus surgeries before AD. Most of our patients were reluctant to undergo surgery because nearly all had undergone multiple previous surgeries.
The overproduction of eicosanoids at both baseline and after aspirin challenge is a well-known feature of AIA that correlates with the severity of the reaction to aspirin. ${ }^{1-3,44}$ Therefore it would be reasonable to expect that AD should decrease eicosanoid production. In our study $\mathrm{AD}$ did not decrease $\mathrm{uLTE}_{4}$ or $\mathrm{p} 9 \alpha, 11 \beta-\mathrm{PGF}_{2}$ levels. Nevertheless, Nasser et $\mathrm{al}^{30}$ observed a substantial increase in $\mathrm{LTE}_{4}$ excretion that continued through up to 9 months of oral AD. Oral AD decreases peripheral monocyte synthesis of $\mathrm{LTB}_{4}$ but not $\mathrm{LTC}_{4}{ }^{29}$ The actual mechanisms underlying the process of $\mathrm{AD}$ might be quite independent from baseline cysLT biosynthesis and might be attributable to decreases in the sensitivities of the airways to $\mathrm{LTE}_{4} \cdot{ }^{45}$ The mechanism might also involve changes in the numbers of leukotriene receptors after $\mathrm{AD},{ }^{16}$ which could be related to the downregulation of IL-4 production. ${ }^{22}$ Interestingly, recent studies have demonstrated that $\mathrm{AD}$ might decrease the IL-4 levels that are deemed responsible for the upregulation of $\mathrm{LTC}_{4}$ synthase by mast cells and the upregulation of cysLT receptors on many immune cell types in patients with AIA. ${ }^{42}$ Recently, a novel mechanism for the augmentation of the transcellular 
conversion of leukotrienes that is mediated by platelet adherence has been reported. ${ }^{46}$

Aspirin has also been postulated to exert direct effects on the biochemical pathways of mast cells. ${ }^{25}$ Chronic AD decreases serum $^{28}$ and sputum $^{22}$ tryptase levels. To the best of our knowledge, ours is the first report to assess the effects of $\mathrm{AD}$ on another important mast cell mediator, $\mathrm{p} 9 \alpha, 11 \beta-\mathrm{PGF}_{2}$. Significant increases in $\mathrm{p} 9 \alpha, 11 \beta-\mathrm{PGF}_{2}$ levels after allergen and aspirin challenges have been observed. ${ }^{1,41,42,47}$ However, in our study neither the actual aspirin challenge nor the chronic AD affected $\mathrm{p} 9 \alpha, 11 \beta-\mathrm{PGF}_{2}$ levels. This discrepancy could be due to differences in mechanisms that govern the release of $\mathrm{p} 9 \alpha, 11 \beta$ $\mathrm{PGF}_{2}$ from mast cells and those that govern tryptase levels, or the small number of patients might have precluded the detection of possible differences.

The main limitation of our study is that the number of subjects was small. We are not the first group to encounter serious difficulties in the recruitment of patients for double-blind studies of $\mathrm{AD}$. A recently published systematic review of the literature related to nasal outcomes of $\mathrm{AD}$ in patients with aspirin-exacerbated respiratory disease found that only 11 of 614 citations met the criteria for analysis and that most of the studies had small sample sizes. ${ }^{13}$ In the first double-blind study, 25 patients with AIA served as their own control subjects by taking 3 different doses of aspirin or placebo for 3 months (there was no parallel ATA group). ${ }^{26}$ Seven patients took 1 tablet ( $325 \mathrm{mg}$ of aspirin), 5 patients took 4 tablets, and 13 patients took 8 tablets. ${ }^{26}$ These numbers are not much greater than those of our study. In the 1980s, a long-term, prospective, blind, placebo-controlled trial was attempted. Over 5 years, only 2 subjects were enrolled. ${ }^{27}$ The patients were not willing to take placebo for an extended period of time. ${ }^{27}$ We readily concede that the actual recruitment of patients with AIA to a placebo-controlled trial of several months' duration is difficult. Additionally, we sought to include patients with ATA who were matched as closely as possible to the patients with AIA in terms of asthma severity and chronic rhinosinusitis with nasal polyps. Only approximately $7 \%$ of the patients with ATA had nasal polyps, whereas nearly all of the patients with AIA did. ${ }^{38}$ Numerous studies comparing patients with AIA and those with ATA have reported that the patients with ATA have much milder and shorter-lasting asthma and rhinosinusitis. In our study the clinical status of the patients with ATA did not differ much from that of the patients with AIA (Table I). To achieve this parity, we had to screen 109 subjects over 4 years, and only 34 were ultimately entered into the trial.

One of the most significant obstacles in the pursuit of $\mathrm{AD}$ in patients with AIA is the necessity of discontinuing aspirin administration because of adverse gastrointestinal effects ( $\mathrm{n}=5$ in our study). ${ }^{5,9,48,49}$ In other studies dropouts have accounted for $13 \%$ to $46 \%$ of subjects, and $6 \%$ to $18 \%$ of these subjects discontinued aspirin because of dyspepsia, abdominal pain, gastritis, or intestinal bleeding. ${ }^{9,26,27,31-33,48,49}$

In conclusion, in this pilot double-blind study we observed moderate and specific beneficial effects of a 6-month AD treatment on bronchial and nasal symptom scores, ICS maintenance doses, and PNIF values that were limited to the patients with AIA. Larger controlled studies of longer duration assessing the efficacy, safety profile, and specific mechanisms of $\mathrm{AD}$, particularly in terms of objective measurements, are therefore strongly recommended.

\section{Key messages}

- Chronic oral AD significantly improved the control of rhinosinusitis and asthma.

- The beneficial effects of chronic oral AD were observed only in the patients with AIA.

\section{REFERENCES}

1. Szczeklik A, Niżankowska-Mogilnicka E, Sanak M. Hypersensitivity to aspirin and non-steroidal anti-inflammatory drugs. In: Adkinson NF Jr, Bochner BS, Busse WW, Holgate ST, Lemanske RF Jr, Simons FER, editors. Middleton's allergy: principles and practice. New York: Mosby; 2009. pp. 1227-40.

2. Laidlaw TM, Boyce JA. Pathogenesis of aspirin-exacerbated respiratory disease and reactions. Immunol Allergy Clin North Am 2013;33:195-210.

3. White AA, Stevenson DD. Aspirin-exacerbated respiratory disease: update on pathogenesis and desensitization. Semin Respir Crit Care Med 2012;33:588-94.

4. Kowalski ML, Makowska JS, Blanca M, Bavbek S, Bochenek G, Bousquet J, et al. Hypersensitivity to nonsteroidal anti-inflammatory drugs (NSAIDs) classification, diagnosis and management: review of the EAACI/ENDA and GA2LEN/HANNA. Allergy 2011;66:818-29.

5. Lee RU, Stevenson DD. Aspirin-exacerbated respiratory disease: evaluation and management. Allergy Asthma Immunol Res 2011;3:3-10.

6. Chang JE, Chin W, Simon R. Aspirin-sensitive asthma and upper airway diseases. Am J Rhinol Allergy 2012;26:27-30.

7. Pezato R, Świerczyńska-Krępa M, Niżankowska-Mogilnicka E, Derycke L, Bachert C, Pérez-Novo CA. Role of imbalance of eicosanoid pathways and staphylococcal superantigens in chronic rhinosinusitis. Allergy 2012;67: 1347-56.

8. Macy E, Bernstein JA, Castells MC, Gawchik SM, Lee TH, Settipane RA, et al Aspirin challenge and desensitization for aspirin-exacerbated respiratory disease: a practice paper. Ann Allergy Asthma Immunol 2007;98:172-4.

9. Williams AN, Woessner KM. The clinical effectiveness of aspirin desensitization in chronic rhinosinusitis. Curr Allergy Asthma Rep 2008;8:245-52.

10. Klimek L, Pfaar O. Aspirin intolerance: does desensitization alter the course of the disease? Immunol Allergy Clin North Am 2009;29:669-75.

11. Moebus RG, Han JK. Immunomodulatory treatments for aspirin exacerbated respiratory disease. Am J Rhinol Allergy 2012;26:134-40.

12. Cortellini G, Testi S, Severino M, Chechi T, Iorno ML, Santucci A, et al, Aspirin challenge/desensitisation before coronary stenting in subjects with history of hypersensitivity. A pragmatic approach. Eur Ann Allergy Clin Immunol 2012; $44: 160-2$.

13. Xu JJ, Sowerby L, Rotenberg BW. Aspirin desensitization for aspirin-exacerbated respiratory disease (Samter's triad): a systematic review of the literature. Int Forum Allergy Rhinol 2013;3:915-20.

14. Patriarca G, Bellioni P, Nucera E, Schiavino D, Papa G, Schinco G, et al. Intranasal treatment with lysine acetylsalicylate in patients with nasal polyposis. Ann Allergy 1991;67:588-92.

15. Nucera E, Schiavino D, Milani A, Del Ninno M, Misuraca C, Buonomo A, et al. Effects of lysine-acetylsalicylate (LAS) treatment in nasal polyposis: two controlled long term prospective follow up studies. Thorax 2000;55:75-8.

16. Sousa AR, Parkih A, Scadding G, Corrigan CJ, Lee TH. Leukotriene-receptor expression on nasal mucosal inflammatory cells in aspirin-sensitive rhinosinusitis. N Engl J Med 2002;347:1493-9.

17. Gosepath J, Schäfer D, Mann WJ. Aspirin sensitivity: long term follow-up after up to 3 years of adaptive desensitization using a maintenance dose of $100 \mathrm{mg}$ of aspirin a day. Laryngorhinootologie 2002;81:732-8.

18. Parikh AA, Scadding GK. Intranasal lysine-aspirin in aspirin-sensitive nasal polyposis: a controlled trial. Laryngoscope 2005;115:1385-90.

19. Ogata N, Darby Y, Scadding G. Intranasal lysine-aspirin administration decreases polyp volume in patients with aspirin-intolerant asthma. J Laryngol Otol 2007;121: 1156-60.

20. Niżankowska-Mogilnicka E, Bochenek G, Mastalerz L, Świerczyńska M Picado C, Scadding G, et al. EAACI/GA2LEN guideline: aspirin provocation tests for diagnosis of aspirin hypersensitivity. Allergy 2007;62:1111-8.

21. Rozsasi A, Polzehl D, Deutschle T, Smith E, Wiesmiller K, Riechelmann H, et al. Long-term treatment with aspirin desensitization: a prospective clinical trial comparing 100 and $300 \mathrm{mg}$ aspirin daily. Allergy 2008;63:1228-34.

22. Katial RK, Strand M, Prasertsuntarasai T, Leung R, Zheng W, Alam R. The effect of aspirin desensitization on novel biomarkers in aspirin-exacerbated respiratory diseases. J Allergy Clin Immunol 2010;126:738-44. 
23. Forer B, Kivity S, Sade J, Landsberg R. Aspirin desensitization for ASA triad patients-prospective study of the rhinologist's perspective. Rhinology 2011;49: 95-9.

24. Havel M, Ertl L, Braunschweig F, Markmann S, Leunig A, Gamarra F, et al Sinonasal outcome under aspirin desensitization following functional endoscopic sinus surgery in patients with aspirin triad. Arch Otorhinolaryngol 2012;270:571-8.

25. Pleskow WW, Stevenson DD, Mathison DA, Simon RA, Schatz M, Zieger RS Aspirin desensitization in aspirin sensitive asthmatic patients: clinical manifestations and characterization of the refractory period. J Allergy Clin Immunol 1982;69:11-9.

26. Stevenson DD, Pleskow WW, Simon RA, Mathison DA, Lumry WR, Schatz M et al. Aspirin-sensitive rhinosinusitis asthma: a double-blind crossover study of treatment with aspirin. J Allergy Clin Immunol 1984;73:500-7.

27. Sweet JA, Stevenson DD, Simon RA, Mathison DA. Long term effects of aspirin desensitization treatment for aspirin sensitive rhinosinusitis asthma. J Allergy Clin Immunol 1990;86:59-65.

28. Bosso JV, Schwartz LB, Stevenson DD. Tryptase and histamine release during aspirin-induced respiratory reactions. J Allergy Clin Immunol 1991;88: $830-7$.

29. Juergens UR, Christiansen SC, Stevenson DD, Zuraw BL. Inhibition of monocyte leukotriene B4 production following aspirin desensitization. J Allergy Clin Immunol 1995;96:148-56.

30. Nasser SMS, Patel M, Bell GS, Lee TH. The effect of aspirin desensitization on urinary leukotriene E4 concentration in aspirin-sensitive asthma. Am J Respir Crit Care Med 1995;151:1326-30.

31. Stevenson DD, Hankammer MA, Mathison DA, Christiansen SC, Simon RA Long term ASA desensitization-treatment of aspirin sensitive asthmatic patients: clinical outcome studies. J Allergy Clin Immunol 1996;98:751-8.

32. Berges-Gimeno MP, Simon RA, Stevenson DD. Long-term treatment with aspirin desensitization in asthmatic patients with aspirin-exacerbated respiratory disease. J Allergy Clin Immunol 2003;111:180-6.

33. Berges-Gimeno MP, Simon RA, Stevenson DD. Early effects of aspirin desensitization treatment in asthmatic patients with aspirin-exacerbated respiratory disease. Ann Allergy Asthma Immunol 2003;90:338-41.

34. Stevenson D, Simon RA. Selection of patients for aspirin desensitization. J Allergy Clin Immunol 2006;116:801-4.

35. Lee RU, White AA, Ding D, Dursun AB, Woessner KM, Simon RA, et al. Use of intranasal ketorolac and modified oral aspirin challenge for desensitization of aspirin-exacerbated respiratory disease. Ann Allergy Asthma Immunol 2010;105: $130-5$.

36. Shah S, Mehta V. Controversies and advances in non-steroidal anti-inflammatory drug (NSAID) analgesia in chronic pain management. Postgrad Med J 2012;88:73-8.

37. Global Strategy for Asthma Management and Prevention, Global Initiative for Asthma (GINA) 2012. Available at: www.ginaasthma.org. Accessed December 2013.

38. Fokkens WJ, Lund VJ, Mullol J, Bachert C, Alobid I, Baroody F, et al. European position paper on rhinosinusitis and nasal polyps 2012. Rhinol Suppl 2012;3:1-298.

39. Lund VJ, Kennedy MD. Staging for rhinosinusitis. Otolaryngol Head Neck Surg 1997:117:35-40.

40. Kumlin M. Measurement of leukotrienes in humans. Am J Respir Crit Care Med 2000;161:102-6.

41. Bochenek G, Niżankowska E, Gielicz A, Świerczyńska M, Szczeklik A. Plasma 9alpha,11beta-PGF2, a PGD2 metabolite, as a sensitive marker of mast cell activation by allergen in bronchial asthma. Thorax 2004;59:459-64.

42. Steinke JW, Payne SC, Borish L. Interleukin-4 in the generation of the AERD phenotype: implications for molecular mechanisms driving therapeutic benefit of aspirin desensitization. J Allergy (Cairo) 2012;2012:182090.

43. Burnett T, Katial R, Alam R. Mechanisms of aspirin desensitization. Immunol Allergy Clin North Am 2013;33:223-36.

44. Swierczynska M, Nizankowska-Mogilnicka E, Zarychta J, Gielicz A, Szczeklik A. Nasal versus bronchial and nasal response to oral aspirin challenge: Clinical and biochemical differences between patients with aspirin-induced asthma/rhinitis. J Allergy Clin Immunol 2003;112:995-1001.

45. Arm JP, O'Hickey SP, Spur BW, Lee TH. Airway responsiveness to histamine and leukotriene E4 in subjects with aspirin-induced asthma. Am Rev Respir Dis 1989; 140:148-53.

46. Laidlaw TM, Kidder MS, Bhattacharyya N, Xing W, Shen S, Milne GL, et al. Cysteinyl leukotriene overproduction in aspirin-exacerbated respiratory disease is driven by platelet-adherent leukocytes. Blood 2012;119:3790-8.

47. Bochenek G, Nagraba K, Niżankowska E, Szczeklik A. A controlled study of 9alpha,11beta-PGF2 (a PGD2 metabolite) in plasma and urine of patients with bronchial asthma and healthy controls after aspirin challenge. J Allergy Clin Immunol 2003;111:743-9.

48. White AA, Stevenson DD. Side effects from daily aspirin treatment in patients with AERD: identification and management. Allergy Asthma Proc 2011:32:333-4.

49. Baker TW, Quinn JM. Aspirin therapy in aspirin-exacerbated respiratory disease: a risk-benefit analysis for the practicing allergist. Allergy Asthma Proc 2011;32: 335-40. 